\title{
The role of concomitant respiratory diseases on the rate of decline in FEV1 among adult asthmatics
}

\author{
D. Sherrill*,\#, S. Guerra*, A. Bobadilla*, R. Barbee*
}

The role of concomitant respiratory diseases on the rate of decline in FEVI among adult asthmatics. D. Sherrill, S. Guerra, A. Bobadilla, R. Barbee. (C) ERS Journals Ltd 2003. ABSTRACT: Several recent reports have presented evidence suggesting that adults with asthma have an accelerated rate of decline in pulmonary function compared with nonasthmatics. However, most of these studies have not taken into account the possible effect of comorbid lung disease in addition to asthma. This study was designed to determine if comorbid respiratory diseases modify or otherwise change the estimates of decline in forced expiratory volume in one second (FEV1).

Study subjects were White, non-Mexican, American participants, who were $\geqslant 20$ yrs of age at the initial survey and had at least one pulmonary function testing. Respiratory disease status, based on self-reported questionnaires and pulmonary function tests, were assessed during 12 surveys spanning a period of up to $20 \mathrm{yrs}$.

There were 2,926 subjects who met the inclusion criteria, $214(7.3 \%)$ had physicianconfirmed asthma, $325(11.1 \%)$ chronic obstructive pulmonary disease (COPD), and $125(4.3 \%)$ both physician-confirmed asthma and COPD. Longitudinal analysis revealed that among those with longstanding asthma, FEV1 values were low but did not decline at a more rapid rate than normal. Likewise, subjects with both asthma and COPD had the lowest levels of FEV1, but also a rate of decline that was not significantly increased. Only those with COPD in the absence of asthma experienced both a low initial FEV1 level and a significantly steeper rate of decline.

Based on these findings, the authors conclude that forced expiratory volume in one second does not decline more rapidly in asthmatics or in those with asthma and chronic obstructive pulmonary disease, compared with nonasthmatics.

Eur Respir J 2003; 21: 95-100.
*Arizona Respiratory Center and \#Arizona College of Public Health, The University of Arizona, Tucson, AZ, USA.

Correspondence: D. Sherrill

University of Arizona

Arizona Respiratory Center

Box 24-5030

Tucson

AZ 85724

USA

Fax: 15206266970

E-mail: duane@resp-sci.arizona.edu

Keywords: Asthma

chronic obstructive pulmonary disease forced expiratory volume in one second longitudinal

Received: February 272002

Accepted after revision: July 22002
During the last 20 yrs there has been a significant increase in both the prevalence and mortality of asthma, despite increases in the understanding of the basic pathophysiology of the disease and the development of very effective therapeutic agents [1,2]. As a result, it has become increasingly important to understand better the natural history of asthma and its long-term consequences, especially in terms of its effect on pulmonary function. Several studies have examined this association, with attention focused primarily on forced expiratory volume in one second (FEV1). Longitudinal studies have attempted to determine the effect of asthma on the decline in FEV1, which occurs with age in adults. This has proven to be a very challenging task due to the complex nature of the disease.

It is well known that asthma has a genetic component that relates to susceptibility and that it also interacts with environmental stimuli that are potential disease triggers [3]. It has also been shown that the timing of exposure to risk factors is equally important [4-6]. Understanding the time course of changes in pulmonary function among asthmatics is critical for better understanding and treating complications related to this complex disease.

In a large general population study in Copenhagen,
Denmark [7], the authors reported that the heightadjusted decline in FEV1 among adult subjects with asthma was greater than that found among nonasthmatics. Participants in this study had up to three FEV1 observations taken over a 15-yr period. Likewise, PEAT et al. [8] compared FEV1 changes in 92 adult subjects with asthma and 186 normal subjects, who had a minimum of four observations over an 18-yr period. They also found that subjects with asthma had a greater rate of decline in FEV1 than those without asthma, although among middle-aged females they found no excess decline. However, neither of these studies took into account other comorbid respiratory diseases that may have confounding effects.

In this study, the relationship between changes in FEV1 and asthma was examined while adjusting for the effects of concomitant respiratory diseases and other factors known to affect pulmonary function measures.

\section{Materials and methods}

Subjects were White, non-Mexican, American participants in the Tucson Epidemiological Study of Airways Obstructive Disease (TESAOD). Detailed 
description of the study design and methods of data collection have been reported previously [9]. Briefly, square blocks in the Tucson area were stratified based on the age of the head of the household, ethnic group and socioeconomic status, representing the sampling frame of the study. There were 3,805 initial participants in 1,655 households enrolled in 1972-1973, with new enrolees added by marriage and births. Data were available for this analysis through the twelfth survey, spanning a period of up to $20 \mathrm{yrs}$. Pulmonary function tests from 11 of the 12 surveys, taken $\sim 1.5-2.0$ yrs apart were available for this analysis. Questions concerning respiratory symptoms, diagnoses and smoking status were asked using self-administered questionnaires during each survey. Subjects were included in this analysis if they were $\geqslant 20$ yrs of age at their initial survey and had at least one pulmonary function measurement (FEV1).

\section{Respiratory disease categories}

Subjects were classified as having chronic obstructive pulmonary disease (COPD) if they responded positively to the question, "During the past year, have you seen a doctor for emphysema?" or "During the past year, have you seen a doctor for chronic bronchitis (CB)?" in any survey. In addition, for subjects reporting $\mathrm{CB}$, it was verified that they had symptoms of cough and phlegm for at least 3 months of the year for at least 2 consecutive yrs. For subjects to be classified as having physician-confirmed asthma, they were required not only to report the presence of asthma but also to have been seen, been given a diagnosis or been treated for asthma by a physician. Subjects were considered to have concomitant respiratory diseases if during at least one survey they reported having both doctor-confirmed COPD and asthma. Subjects who reported having both asthma and COPD, but not during the same survey, were excluded from analyses.

Asthma duration was calculated differently for new and existing asthmatics. For new asthmatics, it was computed as the difference between the first and the last dates where physician-confirmed asthma was reported. For those subjects who reported having asthma at the initial survey (existing), asthma duration was computed based on their reported age of onset.

\section{Pulmonary function testing}

Spirometric tests were performed using the American Thoracic Society Criteria with a pneumotachograph in all except the fourth survey [10]. In this report FEV1 was used.

\section{Statistical methodology}

For comparing the mean rates of decline in FEV1 between disease categories, while adjusting for known confounding factors, a "mixed effects" or "random effects model (REM)" was used [11-13]. The form of the REM is identical to that used in ordinary multiple regression, but the method used to estimate the regression coefficients is modified to account for correlation between repeated measures on the same subject. This model allows subjects to have an unequal number of FEV1 observations that can be at different times for different subjects. It can also include both time-dependent (i.e. variables that were measured each survey) and fixed covariables. Selection of the "best" fitting REM was based on a likelihood ratio test for nested models and Akaike's information criterion for non-nested models [11]. This model has been used in several epidemiological studies for describing longitudinal changes in pulmonary function [14-16].

For the REM analyses, potential confounding factors known to influence FEV1 and its slope such as sex, height and smoking history were included as fixed independent variables. Interactions between respiratory disease categories and confounding factors were tested. All statistical hypothesis tests were performed at the $\alpha=0.05$ significance level assuming twotailed comparisons.

\section{Results}

There were 2,926 subjects who met the inclusion criteria of having at least one pulmonary function test and an initial age $\geqslant 20$ yrs. Fifty-five per cent of the participants were females (table 1). The average age was $\sim 45$ yrs, with males being slightly younger and having higher average body mass indexes than females. There were 214 subjects reporting physicianconfirmed asthma, a prevalence rate of slightly over $7 \%$. There were no significant sex differences. Among asthmatics the average duration of the disease was $>20 \mathrm{yrs}$, which also did not differ significantly by sex. Physicianconfirmed COPD was reported by 325 subjects and was more prevalent among males (13.57\%) than females $(9.12 \%)$. Asthma and COPD were reported concurrently in 125 subjects and were distributed almost evenly among males (4.68\%) and females (3.95\%). Males had a significantly higher smoking history (average pack-yrs 36.91) compared to females (average pack-yrs 25.0), this was also true in each of the respiratory disease categories. When subjects with concomitant diseases were broken down into separate categories for $\mathrm{CB}$, emphysema and asthma, the only significant difference between sexes was that females reported more concomitant asthma and CB $(45.31 \%)$ than males $(19.67 \%)$.

The results of fitting the REM to the longitudinal FEV1 data are listed in table 2 and illustrated in figure 1 . These coefficients can be interpreted the same as the coefficients obtained in ordinary multiple regression. For example, the coefficient for sex, which was coded as 1 for males and 0 for females, indicates that male subjects had on average a 1.3-L higher level of FEV1 then female subjects. Likewise, the "sex by age" coefficient shows that male subjects also have a steeper slope $\left(9 \mathrm{~mL} \cdot \mathrm{yr}^{-1}\right)$ than female subjects. In this model both age and age-squared terms were statistically significant and pack-yrs of smoking was related to lower levels of FEV1. 
Table 1.-Basic descriptive statistics for selected study participants of the Tucson Epidemiological Study of Airways Obstructive Disease

\begin{tabular}{|c|c|c|}
\hline Variable & Males & Females \\
\hline Subjects & $1304(45)$ & $1622(55)$ \\
\hline Initial FEV1 L* & $3.63 \pm 1.16$ & $2.60 \pm 0.75$ \\
\hline Age at enrolment yrs* & $44.06 \pm 20.08$ & $46.13 \pm 19.90$ \\
\hline Mean BMI $\mathrm{kg} \cdot \mathrm{m}^{-2 *}$ & $25.01 \pm 3.70$ & $24.03 \pm 4.43$ \\
\hline Asthma duration yrs & $25.50 \pm 18.20^{\#}$ & $22.10 \pm 17.39$ \\
\hline $\begin{array}{l}\text { Age at time of new } \\
\text { asthma diagnosis }\end{array}$ & $43.33 \pm 24.1$ & $47.6 \pm 21.1$ \\
\hline $\begin{array}{l}\text { Age at time of new } \\
\text { COPD diagnosis* }\end{array}$ & $61.79 \pm 17.1$ & $57.1 \pm 18.8$ \\
\hline FEV1 slope $\mathrm{L} \cdot \mathrm{yr}^{-1} *$ & $-0.031 \pm 0.12^{+}$ & $-0.013 \pm 0.086^{\S}$ \\
\hline Maximum pack-yrs* & $36.91 \pm 31.29^{f}$ & $25.00 \pm 23.00^{\# \#}$ \\
\hline Asthma pack-yrs* & $16.6 \pm 24.5$ & $9.64 \pm 17.9$ \\
\hline COPD pack-yrs* & $50.1 \pm 35.2$ & $28.2 \pm 27.4$ \\
\hline $\begin{array}{l}\text { Asthma and COPD } \\
\text { pack-yrs* }\end{array}$ & $49.9 \pm 35.1$ & $24.3 \pm 31.1$ \\
\hline $\begin{array}{l}\text { Mean number of FEV1 } \\
\text { observations }\end{array}$ & $3.55 \pm 3.12$ & $4.12 \pm 3.21$ \\
\hline $\begin{array}{l}\text { Physician-confirmed } \\
\text { asthma }\end{array}$ & $98(7.52)$ & $116(7.15)$ \\
\hline $\begin{array}{l}\text { New physician-confirmed } \\
\text { asthma }\end{array}$ & $31(32.1)$ & $29(25.0)$ \\
\hline Physician-confirmed COPD* & * 177 (13.57) & $148(9.12)$ \\
\hline $\begin{array}{l}\text { Physician-confirmed asthma } \\
\text { and COPD }\end{array}$ & $61(4.68)$ & $64(3.95)$ \\
\hline \multicolumn{3}{|l|}{$\begin{array}{l}\text { Breakdown of asthma } \\
\text { and COPD }\end{array}$} \\
\hline Asthma and emphysema & $16(26.23)$ & $11(17.19)$ \\
\hline Asthma and $\mathrm{CB}^{*}$ & $12(19.67)$ & $29(45.31)$ \\
\hline $\begin{array}{l}\text { Asthma and CB and } \\
\text { emphysema }\end{array}$ & $33(54.10)$ & $24(37.50)$ \\
\hline
\end{tabular}

Data are presented as mean \pm SD or $\mathrm{n}(\%)$. FEV1: forced expiratory volume in one second; BMI: body mass index; COPD: chronic obstructive pulmonary disease; $\mathrm{CB}$ : chronic bronchitis. ${ }^{\#}: \mathrm{n}=98 ;{ }^{\uparrow}: \mathrm{n}=116 ;^{+} \mathrm{n}=1045 ;{ }^{\S}: \mathrm{n}=1368 ;{ }^{f}: \mathrm{n}=848$; \#\#: $\mathrm{n}=786 .{ }^{*}: \mathrm{p}<0.05$ males versus females.

In general FEV1 did not decline in a simple linear trend, as would be the case if the age-squared term was not statistically significant. Having a significant age-squared term in the model shows that there is acceleration in the rate of decline of FEV1 with increases in age. Although slight, having this term in the model makes the fitted mean curves have a concave downward shape (figs. 1 and 2). In addition, this model explained $75 \%$ of the variation in the FEV1 data with $25 \%$ therefore unexplained.

The effect on FEV1 of having one or more respiratory diseases is illustrated in figure 1 . In the bestfit model (table 2), asthma was statistically significant, with a negative coefficient $(-0.156)$, indicating that subjects with asthma have lower FEV1 levels even after adjusting for the normal decline associated with increases in age. This effect did not differ with age, since the asthma by age term $(-0.004)$ was not statistically significant. This finding suggests that asthmatics have the same slope as nonasthmatics. In contrast, COPD was associated with lower levels of FEV1 and steeper rates of decline (fig. 1), as indicated by the significant COPD by age term (-0.0023). For males, this decline also accelerated slightly with age
Table 2.-Results from the random effects model for predicting forced expiratory volume in one second (FEV1). Data from the Tucson Epidemiological Study of Airways Obstructive Disease

\begin{tabular}{|c|c|c|c|}
\hline Variables & Coefficient & SE & $\mathrm{p}$-value \\
\hline \multicolumn{4}{|l|}{$\begin{array}{l}\text { Anthropometric and } \\
\text { smoking factors }\end{array}$} \\
\hline Sex $($ male=1) & 1.303 & 0.037 & $<0.0001$ \\
\hline Height & 0.045 & 0.002 & $<0.0001$ \\
\hline Pack-yrs of smoking & -0.005 & 0.0004 & $<0.0001$ \\
\hline Age yrs & -0.00017 & 0.0012 & $0.147^{\#}$ \\
\hline \multicolumn{4}{|l|}{ Disease main effects } \\
\hline Asthma & -0.156 & 0.061 & 0.011 \\
\hline COPD & -0.135 & 0.065 & 0.038 \\
\hline Asthma and COPD & -0.593 & 0.111 & $<0.0001$ \\
\hline \multicolumn{4}{|l|}{$\begin{array}{l}\text { Disease effects on rate } \\
\text { of decline in FEV } 1\end{array}$} \\
\hline Asthma by age & -0.0004 & 0.0011 & $0.722^{\#}$ \\
\hline COPD by age & -0.0023 & 0.0011 & 0.042 \\
\hline $\begin{array}{l}\text { Asthma and COPD } \\
\text { by age }\end{array}$ & 0.0002 & 0.0015 & $0.867^{\#}$ \\
\hline COPD by sex by age ${ }^{2}$ & -0.00007 & 0.000011 & $<0.0001$ \\
\hline \multicolumn{4}{|l|}{$\begin{array}{l}\text { Interactions and } \\
\text { nonlinear factors }\end{array}$} \\
\hline \multicolumn{4}{|l|}{$\begin{array}{l}\text { Interactions with } \\
\text { sex (males }=1)\end{array}$} \\
\hline Age by sex & -0.009 & 0.0006 & $<0.0001$ \\
\hline $\begin{array}{l}\text { Asthma and COPD } \\
\text { by sex }\end{array}$ & -0.679 & 0.0908 & $<0.0001$ \\
\hline \multicolumn{4}{|l|}{ Nonlinear factors } \\
\hline $\mathrm{Age}^{2}$ & -0.00017 & 0.000010 & $<0.000$ \\
\hline
\end{tabular}

COPD: chronic obstructive pulmonary disease. ${ }^{\#}$ : results not statistically significant at the $\alpha=0.05$ level, indicating no increased decline in FEV1 compared with the reference category.

as indicated by the significant COPD by sex by agesquared term and the slight curvature in the fitted line. This increased acceleration among males with COPD is also illustrated in figure 2.

Subjects with concurrent asthma and COPD had the lowest levels of mean FEV1 (fig. 1). Their mean FEV1 estimates were significantly lower than all other groups at all ages and males with asthma and COPD were affected more than females. However, even though they had the lowest mean levels, their slope or rate of decline did not differ from that of the reference population, since the asthma and COPD by age term (0.0002) was not statistically significant.

To test if asthma was associated with an increased rate of decline if asthmatics with COPD had not been accounted for, the REM analysis was recalculated with these groups combined (any asthma). These results show that when combined both the main effect of asthma and its slope with age is statistically significant (table 3).

To evaluate the accuracy of the REM slope estimates, a second analysis was conducted where a simple linear regression model was fitted to each subject's FEV1 versus age data to get an estimate of their rate of decline in FEV1 or slope estimate (results not shown). These slopes were then included as the dependent variable in a multiple regression model with the same covariates as the REM (table 2). After 

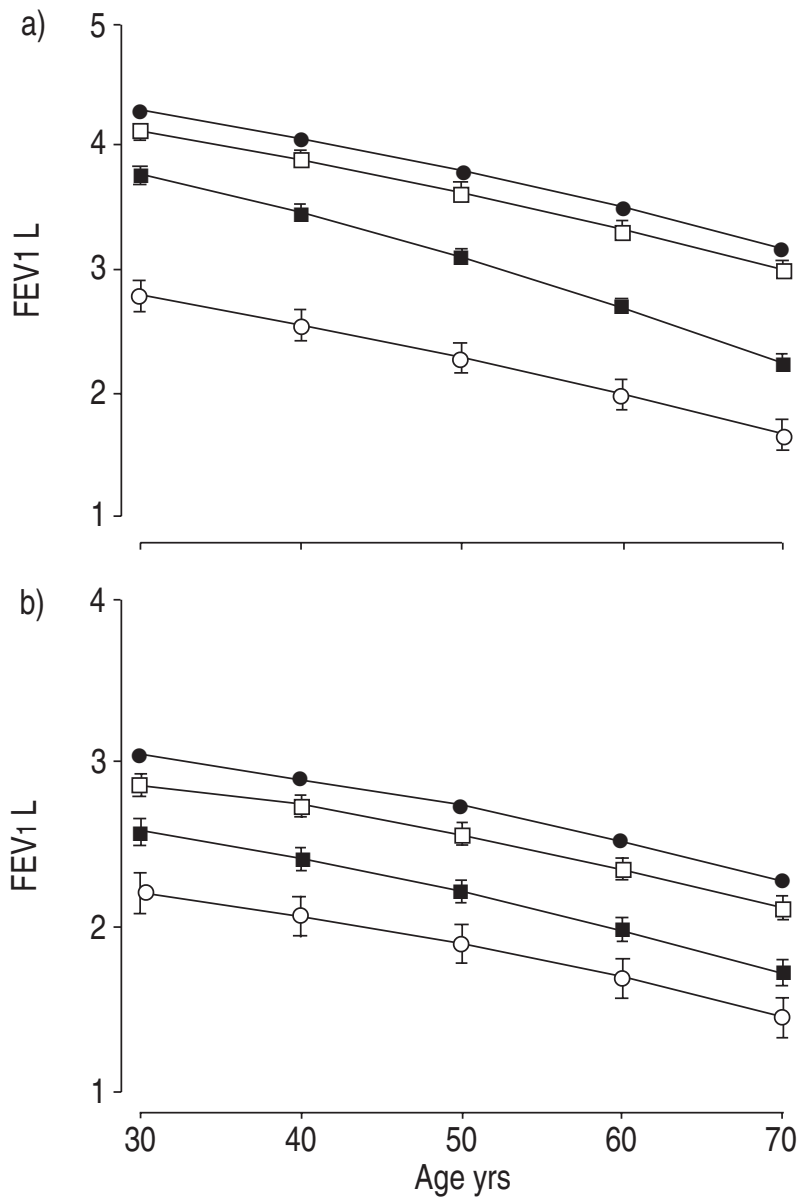

Fig. 1.- Mean forced expiratory volume in one second (FEV1) curves for a) males and b) females with chronic obstructive pulmonary disease (COPD), demonstrating the increased acceleration related to the "sex by age" interaction term (table 2). Results from the Tucson Epidemiological Study of Airways Obstructive Disease. $\bigcirc$ : reference; $\square$ : asthma; $\mathbf{\square}$ : COPD; $\bigcirc$ : asthma and COPD.

adjusting for sex, age and height only COPD had a significant association with the slope of FEV1. Subjects with COPD had mean FEV1 slopes that declined $17 \mathrm{~mL} \cdot \mathrm{yr}^{-1}$ more rapidly than the reference group. Similar to the results found in the REM analysis neither asthma nor asthma plus COPD showed increased rates of decline in FEV1 compared with the reference group, thus confirming the authors' findings using REM.

\section{Discussion}

In contrast to asthma as it occurs in childhood, adults, especially those $>40$ yrs of age, have a high prevalence of comorbid conditions that may impact airway function. The most obvious impact may be on the slope of the yearly decline in FEV1, which is attributed to asthma, when in fact the presence of COPD may be driving that excess decline.

In a 15-yr follow-up study of a general population, LANGE et al. [7] examined the decline in FEV1 in

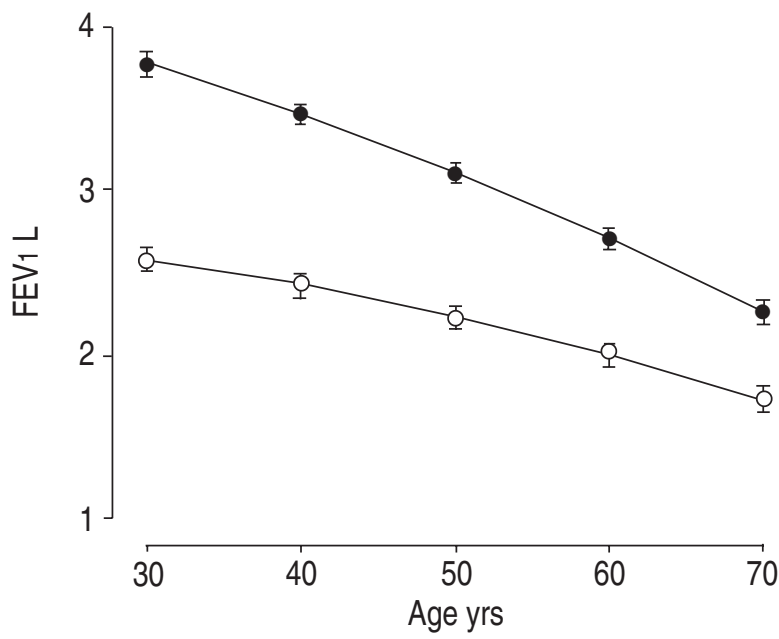

Fig. 2.-Mean forced expiratory volume in one second (FEV1) curves for chronic obstructive pulmonary disease in males (O) and females $(\bigcirc)$ estimated from the fitted random effects model shown in table 2. Results from the Tucson Epidemiological Study of Airways Obstructive Disease.

relation to asthma among 17,506 Danish participants in the Copenhagen City Heart Study. They reported a statistically significant increase in the decline of FEV1 among asthmatics $\left(38 \mathrm{~mL} \cdot \mathrm{yr}^{-1}\right)$ compared with nonasthmatics $\left(22 \mathrm{~mL} \cdot \mathrm{yr}^{-1}\right)$. This study also looked at the effects of mucus hypersecretion, defined as cough and phlegm at least 3 months per year for at least 2 consecutive yrs (CB) on FEV1. They reported that in both sexes, the presence of mucus hypersecretion was associated to a significantly greater decline in FEV1.

Table 3.-Results from the random effects model for predicting forced expiratory volume in one second (FEV 1 ), with asthma categories combined (any asthma). Data from the Tucson Epidemiological Study of Airways Obstructive Disease

\begin{tabular}{|c|c|c|c|}
\hline Variables & Coefficient & SE & $\mathrm{p}$-value \\
\hline \multicolumn{4}{|l|}{$\begin{array}{l}\text { Anthropometric and } \\
\text { smoking factors }\end{array}$} \\
\hline Sex & 1.311 & 0.037 & $<0.0001$ \\
\hline Height & 0.044 & 0.002 & $<0.0001$ \\
\hline Pack-yrs of smoking & -0.0062 & 0.0004 & $<0.0001$ \\
\hline Age yr & -0.0009 & 0.0012 & 0.455 \\
\hline \multicolumn{4}{|l|}{ Disease main effects } \\
\hline Any asthma & -0.255 & 0.054 & $<0.0001$ \\
\hline COPD & -0.0996 & 0.066 & $0.131^{\#}$ \\
\hline \multicolumn{4}{|l|}{$\begin{array}{l}\text { Disease effects on rate } \\
\text { of decline in FEV } 1\end{array}$} \\
\hline Asthma by age & -0.0036 & 0.0009 & $<0.0001$ \\
\hline COPD by age & -0.0028 & 0.0011 & 0.015 \\
\hline COPD by sex by age ${ }^{2}$ & -0.00006 & 0.00001 & $<0.0001$ \\
\hline \multicolumn{4}{|l|}{$\begin{array}{l}\text { Interactions and } \\
\text { nonlinear factors }\end{array}$} \\
\hline $\begin{array}{l}\text { Interactions with sex } \\
\text { Age by sex }\end{array}$ & -0.010 & 0.0006 & $<0.0001$ \\
\hline $\mathrm{Age}^{2}$ & -0.00018 & 0.00001 & $<0.0001$ \\
\hline
\end{tabular}

COPD: chronic obstructive pulmonary disease. ${ }^{\#}$ : results not statistically significant at the $\alpha=0.05$ level. 
However, they did not make the comparison between asthmatics without mucus hypersecretion and nonasthmatics to determine if the observed differences in decline remained statistically significant.

Another study that also looked at the association between comorbid respiratory diseases and changes in lung function was conducted by ALmind et al. [17]. The study included 214 adults with bronchial asthma that had 7 yrs of follow-up. They reported that $58 \%$ of subjects in a nonallergic group, (based on negative skin test results), and $39 \%$ in the allergic group had symptoms that met the criterion of $\mathrm{CB}$, defined as cough and sputum for $>3$ months during at least 2 consecutive yrs. They also found that among the nonallergic subjects the decline in FEV1 was significantly higher for patients with concomitant CB compared with patients without $\mathrm{CB}$. Among allergic subjects, no significant differences were found. These findings illustrate again the importance of taking comorbid diseases and perhaps atopy into account. The authors also found much higher rates of decline in FEV1 than were found in the present study: $95 \mathrm{~mL} \cdot \mathrm{yr}^{-1}$ for the allergic group and $90 \mathrm{~mL} \cdot \mathrm{yr}^{-1}$ for the nonallergic group, which may be a result of the high prevalence of current smokers $(75 \%)$ in their study population. It is important to note that neither of these studies [7, 17] adjusted for comorbid respiratory diseases and when the data in the present study was set without this adjustment it was also found that FEV1 decline was steeper among asthmatics than nonasthmatics (table 3 ).

Similar findings were also reported by BuRRows et al. [18]. In their analysis they examined the rate of decline in FEV1 in subjects that had chronic airflow obstruction at the time of enrolment in the TESAOD. They classified subjects based on clinical characteristics into those with characteristics consistent with asthma $(n=27)$ and those with an emphysematous form of COPD $(n=45)$. A much lower rate of decline in FEV1 was found among the asthmatics than those with the emphysematous form of COPD.

GRIFFITH et al. [19] also reported another study that did not find an increased rate of decline in FEV1 among asthmatics. They examined the longitudinal decline in lung function of 5,242 participants in the Cardiovascular Health Study who were $>65$ yrs of age at enrolment. Each participant had up to three lung function measurements taken over a 7-yr interval. Using the same method of analysis, REMs, they reported that subjects with asthma (former or current) had lower levels of FEV1 than subjects who never had asthma. Asthma also had a significantly larger affect on FEV1 levels for males compared with females. However, there were no significant increases in the rates of decline among asthmatics, most likely due to the fact that they adjusted for emphysema and $\mathrm{CB}$ in their analysis.

In this study, the authors have shown that examining the association between asthma and changes in FEV1 without taking into account other concomitant respiratory diseases would have lead to the conclusion that asthmatics have a steeper rate of decline in FEV1 than healthy nonasthmatics (table 3). Conversely, when this group was reclassified into those with only asthma and those with asthma and COPD there was no statistically significant decline in either category. The question then becomes: if independently neither group has a significant difference in slope, why is it significantly different when they are combined? The reason appears to be that the subjects in the asthma and COPD group tend to be older and have lower lung function than those with just asthma. Therefore, when combined they tend to "pull" the end of the regression line downward making the overall slope more negative. This illustrates the importance of insuring that subjects reporting to have asthma do not have other respiratory illnesses when assessing the relationship between asthma and changes in FEV1. However, the possibility that "statistical power" was increased by combining the two groups cannot be ruled out.

Another issue relating to the FEV1 among the asthma and COPD group is if these subjects do not have more rapid rates of decline, how did they get such low levels of FEV1 (fig. 1)? Either they had a phase of rapid decline prior to being assessed in this study, or they were low to start with, perhaps from birth, and have just been tracking at substantially lower levels. The former theory is supported by the findings of ULRIK and LANGE [20]. They analysed data from a large epidemiological study, The Copenhagen City Heart Study, which consisted of 10,952 subjects, 20-90 yrs of age, followed over a 5-yr period. Using multiple regression models they found a higher rate of decline in FEV1 in subjects with new asthma, but no differences among those with chronic asthma, compared with nonasthmatic subjects. Another study by Postma and Lebowitz [21], on this same Tucson population, looked at the rates of decline among subjects reporting concurrent asthma and $\mathrm{CB}$ and found that they had steeper rates of decline in FEV1 than subjects with asthma as the sole diagnosis.

The authors elected to combine subjects with CB and emphysema into one COPD category. Having indicator variables for all combinations of asthma, emphysema and $\mathrm{CB}$ would have resulted in some groups having very small sample sizes and greatly reduced statistical power. However, to assess the impact of combining emphysema and $\mathrm{CB}$ on these findings, the REM analysis was conducted with the categories broken down as listed in table 1, and still no statistically significant difference in the slopes was found when compared with the reference group.

For subjects in this study to be classified as having concomitant respiratory diseases they had to report having both diseases during the same survey. This requirement was based on the results reported by DoDGE et al. [22] where they found different relationships between lung function and respiratory diseases depending on the order and concurrence.

Other investigators have reported increased mucus hypersecretion among adult asthmatics, even among nonsmokers, and have also reported that asthmatics with mucus hypersecretion have lower levels of pulmonary function [23]. This may reflect badly treated or more severe cases of asthma. In the current study, the possibility that some of the subjects that were classified as having CB may have been asthmatics that 
had not yet received the asthma label cannot be ruled out. This potential misclassification could affect results in that some subjects in the asthma and COPD and COPD alone groups may have actually belonged to the asthma group. Each of these cases would be considered differential misclassification, since it would have made it more difficult to reject the null hypothesis of no difference, suggesting that the estimated mean values for these groups may indeed underestimate the true level.

The REM analysis included all subjects $>20$ yrs of age that had at least one pulmonary function measurement. Subjects with a single observation can contribute important information towards the intercept estimates; however, since a single observation has no slope information their observations do not contribute to the slope estimates [11].

Based on the results of this study, the authors would conclude that forced expiratory volume in one second does not decline more rapidly in asthmatics or even in those with asthma and chronic obstructive pulmonary disease compared with nonasthmatics. However, subjects with asthma and chronic obstructive pulmonary disease have much lower mean levels of forced expiratory volume in one second than either subjects with asthma or chronic obstructive pulmonary disease alone.

\section{References}

1. Gergen PJ, Weiss KB. The increasing problem of asthma in the United States. Am Rev Respir Dis 1992; 144: 823-824.

2. National Center for Chronic Diseases Prevention and Health Promotion. Asthma-United States, 1980-1990. MMWR 1992; 41: 733-735.

3. Duffy DL, Mitchell CA, Martin NG. Genetic and environmental risk factors for asthma - a Cotwin-control study. Am J Respir Crit Care Med 1998; 157: 840-845.

4. Sherrill DL, Stein R, Kurzius-Spencer M, Martinez F. On the early sensitization to allergens and development of respiratory symptoms. Clin Exp Allergy 1999; 29: 905-911.

5. Peat JK, Salome CM, Woolcock AJ. Longitudinal changes in atopy during a 4-year period: relation to bronchial hyperresponsiveness and respiratory symptoms in a population sample of Australian school children. J Allergy Clin Immunol 1990; 85: 65-74.

6. Gibson NA, Palmer L, Young S. Association between airway responsiveness (AR) at 1 month of age, and $\mathrm{AR}$ and development of asthma/atopy at 6 years of age. Am J Respir Crit Care Med 1995; 151: A468.

7. Lange P, Parner J, Vestbo J, Schnohr P, Jensen G. A 15 -year follow-up study of ventilatory function in adults with asthma. N Engl J Med 1998; 339: 1194-1200.

8. Peat JK, Woolcock AJ, Cullen K. Rate of decline of lung function in subjects with asthma. Eur J Respir Dis 1987; 70: 171-179.

9. Lebowitz MD, Knudson RJ, Burrows B. The Tucson epidemiological study of obstructive lung disease, I: methodology and prevalence of disease. Am J Epidemiol 1975; 102: 137-152.

10. American Thoracic Society Statement. Snowbird workshop on standards of spirometry. Am Rev Respir Dis 1979; 119: 831-838.

11. Sherrill DL, Viegi G. On modeling longitudinal pulmonary function data. Am J Respir Crit Care Med 1996; 154: S217-S222.

12. Laird NM, Ware JH. Random effect models for longitudinal data. Biometrics 1982; 12: 963-974.

13. Ware JH. Analysis of longitudinal data: choosing and interpreting regression models. Eur Respir J 1993; 6: 325-327.

14. Tager IB, Kunzli N, Ngo L, Balmes J. Methods development for epidemiologic investigations of the health effects of prolonged ozone exposure. Part I: Variability of pulmonary function measures. Research Report - Health Effects Institute. 1998; 81: 109-121.

15. Sherrill DL, Holberg CJ, Enright PL, Lebowitz MD, Burrows B. Longitudinal analysis of the effects of smoking onset and cessation on pulmonary function. Am J Respir Crit Care Med 1994; 149: 591-597.

16. Vacek PM, Mickey RM, Bell DY. Application of a two-stage random effects model to longitudinal pulmonary function data from sarcoidosis patients. Stat Med 1989; 8: 189-200.

17. Almind $\mathrm{M}$, Viskum $\mathrm{K}$, Evald $\mathrm{T}$, Dirksen $\mathrm{A}$, Kok-Jensen A. A seven-year follow-up study of 343 adults with bronchial asthma. Dan Med Bull 1992; 39: $561-565$.

18. Burrows B, Bloom JW, Traver GA, Cline MG. The course and prognosis of different forms of chronic airways obstruction in a sample from the general population. N Engl J Med 1987; 317: 1309-1314.

19. Griffith KA, Sherrill DL, Siegel EM, Manolio TA, Bonekat HW, Enright PL. Predictors of loss of lung function in the elderly: The Cardiovascular Health Study. Am J Respir Crit Care Med 2001 163: 61-68.

20. Ulrik CS, Lange P. Decline of lung function in adults with bronchial asthma. Am J Respir Crit Care Med 1994; 150: 629-634.

21. Postma DS, Lebowitz MD. Persistence and new onset asthma and chronic bronchitis evaluated longitudinally in a community population sample of adults. Arch Intern Med 1995; 155: 1393-1399.

22. Dodge R, Cline MG, Burrows B. Comparisons of asthma, emphysema, and chronic bronchitis diagnoses in a general population sample. Am Rev Respir Dis 1986; 133: 981-986.

23. Burrows B, Barbee RA, Cline MG, Knudson RJ, Lebowitz MD. Characteristics of asthma among elderly adults in a sample of the general population. Chest 1991; 100: 935-942. 